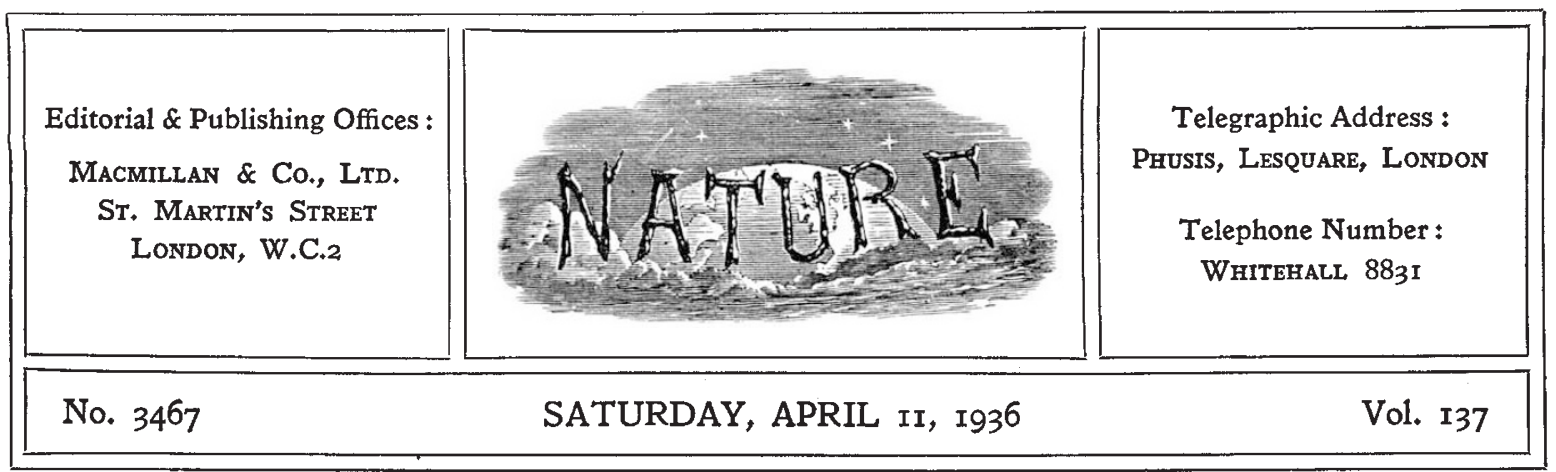

\title{
Eugenics and Society
}

$\mathrm{I}^{\mathrm{F}}$ the Eugenies Society fashions its attitudes and policies in accord with the ideas and ideals presented to it in the Galton Lecture for 1936 delivered on January 17 by Prof. Julian Huxley, it will surely receive many and powerful reinforce. ments. Eugenics is destined to become part of the religion of the future, or of whatever complex of sentiments which may then take the place of organised religion. But, before it can become a soul-compelling ideal, it must first achieve precision and efficiency as a branch of applied science. It must devise new techniques which can cope with plurality of causation and plurality of effect, and can also design and explain an experiment in which rigorous control is not possible. Eugenics is much more than human genetics, for though it certainly aims at the improvement of the human race by means of the improvement of its genetic qualities, its policies must never disregard the obvious fact that such improvement implies a knowledge not only of the type but also of its habitat and destiny. Improvement, whatever form this may take, can only be realised in a certain kind of environment, and therefore, to the eugenist, a study of the environment must accompany a study of the genetic constitution of the stock.

In all comparisons of individuals, of social classes and of ethnic groups, it is impossible to assert that any observed difference in characterisation is a reflection of some fundamental genetic dissimilarity until it has been shown that it is not due, in the whole or part, to the impress of different environmental forces. Until the environmenthousing, diet, education-is equalised, we have no right to the view that certain groups or classes who differ among themselves in visible characters are genetically dissimilar, and that therefore in relation to the conditions of the social environment some are superior and others inferior. It is the case that different ethnic groups, for example, differ in regard to the amount and to the range and type of variability of physical characters, and that these differences are, in the main, genetic. It is safe to assume, further, that these groups will be shown to differ genetically also in respect of intellectual and emotional characters, both quantitatively and qualitatively. But it is unlikely that these differences can ever account for the prejudices and antagonisms that separate the peoples.

Racial theories are nothing more or less than rationalisations of political prejudices, as shown by Prof. Huxley in his Friday evening discourse at the Royal Institution on March 27. So long as a half-caste remains an outcast, it is impossible to assess his biological or social worthiness. The social environment itself exercises a selective influence, attracting to it certain biological types and repelling others, favouring certain evolutionary trends and embarrassing others.

The eugenist must therefore consider, as a eugenist, the particular political and social structure of the community with which he deals. $\mathrm{He}$ must ask whether or not social success is synonymous with ultimate biological and human values, and also whether or not a competitive and individualist system, based on private capitalism and public nationalism, is in its essence of a nature eugenic or dysgenic. If the social system is not itself satisfactory, then the eugenist must aim at its transformation. Eugenists must familiarise themselves with the outlook and the concepts of sociology, with the technique and practice of social reform, for these are an indispensable part of the machinery the eugenists need if they are to realise their aims. 